\title{
ALGUNAS HAZAÑAS DE LAS MUCHAS DE DON GARCÍA HURTADO DE MENDOZA, COMEDIA GENEALÓGICA DE NUEVE INGENIOS
}

\author{
Carlos Mata Induráin \\ GRISO-Universidad de Navarra \\ cmatain@unav.es
}

RESUMEN / ABSTRACT

\begin{abstract}
Algunas hazañas de las muchas de don García Hurtado de Mendoza, marqués de Cañete, pieza escrita en colaboración por nueve ingenios encabezados por Luis de Belmonte Bermúdez, se representó y publicó en Madrid en 1622. Se trata de una comedia genealógica de encargo, que formó parte de la campaña de propaganda emprendida por la familia de los Hurtado de Mendoza para prestigiar la figura de don García Hurtado de Mendoza, cuarto marqués de Cañete, quien como gobernador de Chile (1557-1561) había logrado notables avances en la pacificación del rebelde territorio de Arauco, pero cuyos méritos no quedaron reconocidos por Alonso de Ercilla en La Araucana. Se estudia, sobre todo, la imagen que la pieza ofrece del noble personaje en el contexto de su actuación en la guerra de Arauco, la cual generó en el Siglo de Oro un abundante corpus de obras literarias.
\end{abstract}

Palabras Clave: teatro español del Siglo de Oro, comedia genealógica, teatro y mecenazgo, García Hurtado de Mendoza, guerra de Arauco, Luis de Belmonte Bermúdez, comedia en colaboración.

Algunas hazañas de las muchas de don García Hurtado de Mendoza, marqués de Cañete, collaborated play by nine playwrights headed by Luis Belmonte Bermúdez, was represented and published in Madrid in 1622. It's a genealogical comedy, which was part of the propaganda campaign launched and paid by Hurtado de Mendoza's family, in order to give prestige to the figure of don Garcia Hurtado de Mendoza, 4th Marquis of Cañete, who as Governor of Chile (1557-1561) had achieved remarkable progress in pacifying the rebellious territory of Arauco, but whose merits were not recognized by Alonso de Ercilla in La Araucana. The article studies the image of don Garcia in the context of the Arauco War, which generated a rich corpus of literary works in the Spanish Golden Age. 
KEY WORDS: Spanish Drama of the Golden Age, genealogical comedy, theatre and patronage, Garcia Hurtado de Mendoza, Arauco war, Luis de Belmonte Bermúdez, collaborated comedy.

En el teatro español del Siglo de Oro existen varias piezas que tienen como tema la conquista de Chile y la prolongada guerra de Arauco. Dentro de ese corpus, hay algunas comedias que fueron encargadas por la propia familia de los Hurtado de Mendoza (primero por el mismo don García y luego por su hijo don Juan Andrés) con la finalidad de prestigiar la figura del cuarto marqués de Cañete, quien en su etapa como gobernador de Chile (1557-1561) había logrado notables avances en la pacificación del rebelde territorio de Arauco, pero cuyos méritos e importancia no quedaron reconocidos por Alonso de Ercilla en su famosa Araucana. Para tratar de contrarrestar aquel voluntario olvido se preparó un amplio programa de propaganda que incluyó no solo varias obras de teatro, sino también crónicas, biografías, poemas épicos, etc. Las tres piezas teatrales que presentan ese carácter de "obras de encargo" son Arauco domado de Lope de Vega, la más famosa y conocida, la que más bibliografía ha generado (¡Lope es Lope!) y asimismo la que parece estar al comienzo de la serie (aunque su publicación se produce en 1625, su fecha de redacción es bastante más temprana, en torno a 1599-1603); El gobernador prudente de Gaspar de Ávila (puede datarse en torno a 1624-1625, pero no sería publicada hasta 1663); y la obra que hoy me ocupa, Algunas hazañas de las muchas de don García Hurtado de Mendoza, marqués de Cañete, comedia "perpetrada" -y con la elección de esta palabra adelanto ya un juicio valorativo sobre su escasa calidad dramático-literaria- por nueve ingenios capitaneados por Luis de Belmonte Bermúdez, la cual se representó y publicó en Madrid en $1622^{2}$.

Algunas hazañas es una obra que hay que estudiar en el contexto del mecenazgo teatral y literario, concretamente en la categoría de las comedias genealógicas de encargo (también denominadas comedias histórico-políticas). Ver Ferrer, Sommer-Mathis et al. y Zugasti. Como es de suponer, estos encargos nobiliarios para escribir elogiosas piezas genealógicas de algún personaje de la familia dejaban pingües beneficios a los dramaturgos (o a los autores literarios, en general, pues también hay encargos en otros géneros distintos del teatro).

Para el análisis de esta pieza ver especialmente Vega García-Luengos 204-210; Antonucci 32-35; Lee 184-203; Dixon 84-85; Lerzundi, Arauco 25-32 e "Introducción"; y Castillo 115-125. Cito por la edición moderna de Lerzundi, que cuenta con numeración de los versos, pero modificando levemente, sin indicarlo, algunas grafías y la puntuación. 
En sus cuatro años de gobernación, 1557-1561, el marqués de Cañete había impulsado la pacificación de aquel "Flandes indiano" 3 que fue Chile (tras la muerte de Pedro de Valdivia, la rivalidad por el poder entre Aguirre y Villagra había favorecido la rebelión araucana, comandada por Lautaro, que se prolongaría, con intermitencias de paz más o menos estable, durante muchas décadas). Las citadas tres comedias de encargo presentan, como es natural en piezas que nacen con voluntad panegírica, varios puntos en común a la hora de mostrar la figura de don García con perfiles positivos, si bien cada una de ellas ofrece sus propias peculiaridades o focaliza su atención en aspectos diferentes. No puedo detenerme ahora en un comentario detallado de lo que sucede en Arauco domado y en El gobernador prudente ${ }^{4}$, pero baste recordar que en estas dos piezas -y lo mismo sucederá en Algunas hazañas - el elogio de don García lo vamos a encontrar puesto en boca de muy distintos personajes y se va a llevar a cabo desde múltiples perspectivas. Todos, incluidos los enemigos, ponderarán su nobleza, prudencia, valor, generosidad, sentido de la justicia, etc. Y, por supuesto, también sus propios hechos y sus palabras en escena servirán para trazar su idealizado retrato teatral. El reconocimiento de sus méritos y virtudes se reitera de forma continuada: lo elogiarán todos, españoles y araucanos, hombres y mujeres, jóvenes y viejos, con frases y expresiones que, consideradas en su totalidad, vienen a conformar un acabado panegírico del personaje. En efecto, todas las comedias nos lo presentan como un general valiente y previsor, generoso, nada codicioso (no son posibles las acusaciones de codicia porque, se insiste, la tierra chilena es pobre), un magnífico gobernador, piadoso y cristiano (esto, sobre todo, en El gobernador prudente), fiel a su rey y con un firme proyecto de pacificar el rebelde territorio araucano para lograr la consecución de una monarquía católica y universal.

En suma, en estas piezas dramáticas se destacan las virtudes de don García como vasallo leal a su monarca, militar avisado y gobernador justo. El resultado de conjunto, como no podía ser de otra manera, es una visión

Por emplear el marbete que acuña el jesuita Diego de Rosales en el título de su crónica; la asimilación de Chile con Flandes, con distintos valores y significados, ya tenía precedentes de uso en otros autores (ver ahora el valioso trabajo de Baraibar, en este mismo volumen).

En otros trabajos he analizado la imagen idealizada que de don García ofrecen Arauco domado y El gobernador prudente. Ver Mata Induráin, "El imaginario indígena en el Arauco domado" y "El imaginario indígena y la justificación...". 
altamente idealizada y panegírica del personaje. Ahora bien, cabe añadir - para cerrar estos comentarios preliminares- que ninguna de estas obras logró elevar a don García a la categoría de héroe histórico-literario, mítico, capaz de pervivir en el imaginario colectivo, tal como concluyera con certeras palabras Germán Vega García-Luengos:

En resumidas cuentas, esta historia que rematan los nueve ha sido una empresa de todos contra Ercilla, pero con Ercilla, con sus armas y con su admiración. A pesar del sólido prestigio de tantos espadones en lucha, decidieron el triunfo final los méritos literarios. Y es que Alonso de Ercilla cantó pro domo sua, con el calor de las cosas cordiales, mientras que Lope, Mira, Belmonte, y tantos otros asalariados de los Hurtado, lo hicieron por la casa y por la causa de los demás. El Marqués de Cañete nunca consiguió desplazar, ni siquiera acompañar a Caupolicán en la galería de los mitos áureos (210; ver también Morán Martín 86; y Castillo 90-91).

Sin duda, al momento de componer La Araucana, Ercilla no habría olvidado todavía el grave incidente personal que tuvo lugar entre él y don García en la ciudad de La Imperial en 1558, y esta es la razón que explicaría el no haber dado el suficiente relieve a la figura de don García Hurtado de Mendoza. Recordaré que Pedro de Oña, en el exordio de su Arauco domado, dejó consignado que una de las razones que le movían al componer su poema era "ver que tan buen autor, apasionado, / os haya de propósito callado". Y si, como ingeniosamente señala Vega García-Luengos, "La mancha de literatura con literatura se quita" (201), es fácil de comprender que la familia Hurtado de Mendoza encargara y patrocinara económicamente una extensa e intensa campaña de propaganda que se desarrolló, a lo largo de una treintena de años aproximadamente, en América y en España, en dos etapas cronológicas cuyos principales hitos pueden resumirse así: en Perú, con la redacción de obras encargadas por el marqués de Cañete, como la crónica de Mariño de Lobera (1589) y el Arauco domado de Oña (1596); y más tarde en España, primero por iniciativa del propio don García (Arauco domado de Lope, en el quicio de los siglos XVI y XVII), y luego, tras su muerte ocurrida en 1609, por encargo de su hijo don Juan Andrés, correspondiendo a esta nueva fase la biografía de Cristóbal Suárez de Figueroa del año 1613 y las comedias genealógicas de los nueve ingenios (1622) y de Gaspar de Ávila (en torno a 1624-1625, coincidiendo con la entrega a las prensas, en ese año de 1625, de la comedia lopesca). 


\section{DATOS EXTERNOS, ESTRUCTURA INTERNA Y FUENTES}

Resumiré a continuación, de forma muy somera, los principales datos externos sobre la comedia (autoría y datación, representación y publicación), así como los relativos a su estructura interna y las fuentes manejadas por los autores, dejando para otro apartado el comentario de algunas valoraciones que ha ofrecido la crítica acerca de Algunas hazañas.

La pieza que nos ocupa, que ha sido calificada por Patricio C. Lerzundi como "tragicomedia histórica" siendo el coordinador del proyecto el sevillano Luis de Belmonte Bermúdez, quien estaba en México hacia 1604 y en 1605 había pasado a Lima; allí conoció a Pedro de Oña y al propio don García Hurtado de Mendoza, de forma que "pudo informarse en detalle de todos los hechos históricos relacionados con la conquista de Chile" $(25)^{6}$. Los demás dramaturgos que colaboraron en la escritura de la pieza fueron Juan Ruiz de Alarcón, Luis Vélez de Guevara, Antonio Mira de Amescua, Guillén de Castro, Fernando de Ludeña, Jacinto de Herrera y Sotomayor, Diego de Villegas y Francisco de Tapia y Leyva, conde del Basto 7 . Y aunque varios de ellos eran dramaturgos de reconocido prestigio y competencia (los cuatro primeros ocupaban un lugar destacado en el panorama teatral del momento, mientras que los otros cuatro eran menos importantes), la calidad del producto resultante de esta colaboración a tantas manos no podía menos que resentirse.

La existencia de piezas dramáticas escritas en colaboración es fenómeno bien conocido -y últimamente bastante estudiado- en el teatro del Siglo de Oro español: para atender la fuerte demanda del público de los corrales de comedias, que exigía continuas novedades en los títulos representados, los dramaturgos debían trabajar muchas veces contra el reloj para cumplir con los plazos de los compromisos acordados con los autores de las compañías, y una forma de hacerlo con más comodidad consistía precisamente en repartirse el trabajo entre varios. Lo más habitual era la colaboración entre tres ingenios, a razón de una jornada para cada pluma, y en cambio resulta mucho más

\footnotetext{
"Publicada en 1622 con el rótulo de comedia, atendiendo a su temática, Algunas hazañas... cabe dentro de la clasificación de "tragicomedia histórica'” (Lerzundi 2).

Para el personaje histórico, ver la biografía de Cristóbal Suárez de Figueroa, Hechos de don Hurtado García de Mendoza ..., y el trabajo moderno de Campos Harriet.

Datos de los nueve autores en Lerzundi, Arauco 25-30.
} 
excepcional -aunque sin ser tampoco caso único- el de una comedia escrita a nueve manos ${ }^{8}$. Como bien señala Lerzundi, "Lo que llama la atención en Algunas hazañas..., más que el hecho de que sea una obra escrita en colaboración, es que es una de las pocas que cuenta con nada menos que nueve autores" (25). Ya Luis Fernández-Guerra y Orbe evocaba, a la altura de 1871, varias de las características de esta redacción en colaboración, al tiempo que apuntaba otras circunstancias atingentes a la representación y publicación en formato lujoso de la pieza que nos ocupa:

Muerto el piadoso príncipe [Felipe III], sucediéndole su hijo, con destinada afición a las musas del teatro, juzgó don Juan Andrés que en la escena se debía también presentar con toda su grandeza la figura del noble don García; y encomendó la tarea de disponer una comedia en su elogio al poeta Luis de Belmonte Bermúdez, que le había conocido y debido atenciones, siendo virrey del Perú, en el año de 1605 . Belmonte, para dar mayor importancia y realce a la ofrenda, llamó a la parte del trabajo y de la gloria a algunas personas a quienes estimaba por amigos y muy sutiles ingenios. Reuniéronse nueve colaboradores, sin duda como observa con su habitual penetración el señor Hartzenbusch, para representar las nueve musas; y tomando por guía el libro del doctor maldiciente [los Hechos... de Suárez de Figueroa], trabajaron la comedia intitulada Algunas hazañas de las muchas de don García Hurtado de Mendoza, marqués de Cañete, dedicándola a su hijo y sucesor el gentilhombre de la cámara de $\mathrm{Su}$ Majestad. Representose, con extraordinario aparato, riqueza de trajes y admirable perspectiva, el año de 1622; y se imprimió lujosamente, aderezándola con dedicatoria y prólogo al lector y con los nombres de los poetas, y expresión de la parte de trabajo que a cada cual había correspondido (358).

¿Cuál es la relación que unía a los nueve colaboradores, y a ellos a su vez con Lope, autor de la precedente comedia del mismo tema Arauco domado? Reduciéndolo a lo esencial, se trata de la coincidencia de casi todos ellos

\footnotetext{
Se suele recordar el caso similar de La mejor luna africana y Rey Chico de Granada, estudiada por Carrasco Urgoiti y más recientemente por Matas Caballero. En cualquier caso, no me detengo en los mecanismos de la escritura en colaboración (tema que cada vez va contando con más bibliografía: ver Matas Caballero, "El Arte nuevo" y Cassol y Matas Caballero, en prensa), sino que me centro en la caracterización del personaje a lo largo de la comedia en su conjunto, haciendo abstracción de la autoría de cada segmento.
} 
en las justas poéticas madrileñas en honor de San Isidro de los años 1620 y 1622, tal como ha explicado Lerzundi, entre otros críticos:

Se ha visto que el interés de Lope por el tema de Arauco se remonta a 1598 y a través de muchas fuentes no necesariamente por conseguir el favor de los Cañete. Por otra parte, Luis de Belmonte estuvo en contacto directo con Pedro de Oña y con don García Hurtado de Mendoza entre los años 1605 y 1606 en el Perú.

Durante las justas poéticas de San Isidro de 1620 y 1622, en donde se reúne la mayoría de los nueve ingenios, Lope había servido como secretario y organizador de ellas. En la justa de 1620 concurrieron Luis de Belmonte, Jacinto de Herrera, el conde del Basto, Guillén de Castro y Diego de Villegas; en la justa de 1622 concurrieron Mira de Amescua, Guillén de Castro, el conde del Basto, Diego de Villegas y Fernando de Ludeña. Se deduce que es a partir de la justa de 1620 cuando comienza a formalizarse el proyecto de Algunas hazañas... (31).

¿Y cuál fue la intervención que tuvo cada uno de ellos en el proyecto común? No es mi propósito analizar las características de esta comedia en cuanto tal obra en colaboración, para valorar la aportación de cada poeta y explicar cómo se produce el ensamblaje de las distintas piezas, sino presentar cómo aparece tratada la figura de don García en el conjunto. Me limitaré aquí a dejar constancia del orden de las aportaciones hechas por cada dramaturgo y del número de versos de que constan. Hay que recordar que la dedicatoria a don Andrés Hurtado de Mendoza, así como las palabras dirigidas al "Lector", son de Belmonte, como seguramente es suyo también el plan organizativo general de la obra y la labor de coordinación de los distintos ingenios. Los versos de la comedia se distribuyen así: en la Jornada I, los vv. 1-260 (un total de 260 versos), son de Antonio Mira de Amescua; los vv. 261-404 (144), de Francisco de Tapia y Leyva, conde del Basto; y los vv. 405-1218 (814), de Luis de Belmonte. En la Jornada II, los vv. 1219-1584 (367) corresponden a Juan Ruiz de Alarcón; los vv. 1585-1956 (372), a Luis Vélez de Guevara; y los vv. 1957-2119 (163), a Fernando de Ludeña. En fin, en la Jornada III escribe los vv. 2120-2471 (352) Jacinto de Herrera y Sotomayor; los vv. 2472-2701 (230), Diego de Villegas; los vv. 2702-3045 (344), Guillén de Castro, y remata la faena Belmonte, que es el único que repite, con los vv. 3046-3195 (150).

En cuanto al contenido, a los hechos de la guerra de Arauco referidos por la comedia, tampoco es este el momento de copiar por extenso el resumen 
argumental $^{9}$; baste para mi propósito con decir que la acción se inicia tras la muerte de Valdivia y la llegada del nuevo gobernador, el mozo don García, y termina con el cautiverio, la conversión al cristianismo y la muerte del toqui Caupolicán.

Por lo que respecta a las fuentes manejadas por los autores -aspecto que en esta ocasión no puedo detenerme a comentar con detalle-, baste con decir que los nueve ingenios se remontan, en última instancia, a aquella original de la que bebieron todos quienes escribieron sobre la guerra de Arauco y sus gentes: La Araucana de Ercilla, a la que hay que sumar el Arauco domado de Oña, los Hechos de don García Hurtado de Mendoza... de Cristóbal Suárez de Figueroa y también el Arauco domado de Lope (recordemos que, aunque publicada en 1625, la comedia del Fénix habría sido la primera de la serie, con probable fecha de redacción en el período de $1599-1603)^{10}$. No existen, en cualquier caso, mayores pretensiones de fidelidad a los hechos históricos, aspecto resaltado por Vega García-Luengos: "La comedia no sólo es la culminación de ese empeño de mitificación interesada de Don García, también marca el extremo al que llega la deformación de unos hechos ocurridos tres cuartos de siglo antes" (206).

Gracias a los asientos contables correspondientes a los gastos de la comedia, recuperados y estudiados por Varey y Shergold ${ }^{11}$, sabemos que fue representada en Palacio, en el cuarto de la Reina, entre el 5 de octubre de 1622 y el 8 de febrero de 1623, en la que fue la primera campaña teatral cortesana de Felipe IV; y que la obra se llevó a las tablas con mucha pompa y riqueza de decorados, a cargo de dos compañías, la de Cristóbal de Avendaño y la de Pedro de Valdés, algo que no resultaba estrictamente necesario atendiendo al reparto. El objetivo habría sido entonces el de dar la mayor vistosidad

$9 \quad$ Ver Lerzundi, Arauco 31-32; y Vega-García Luengos 208-210.

10 Ver Lerzundi, Arauco 74-76. Escribe Antonucci que "La secuencia argumental es la misma de Arauco domado de Lope; pero ahora el influjo del poema de Oña es prácticamente nulo, y la comedia sigue más bien los cantos XVI-XXXIV de La Araucana de Ercilla" (32).

Ver Varey y Shergold, "Some Palace Performances” y Comedias en Madrid, 128. Escribe Ferrer: "No podemos saber a ciencia cierta hasta qué punto la obra compuesta por Juan Ruiz de Alarcón, Mira y los otros dramaturgos sobre las hazañas de García Hurtado de Mendoza se escribió bajo el impulso de la familia o a iniciativa de los mismos dramaturgos, pero la obra fue representada ante la reina entre octubre de 1622 y febrero de 1623" (116). Vega García-Luengos recuerda el detalle de que "En la documentación palatina la comedia recibe los títulos de Las victorias del Marqués de Cañete y Las hazañas del Marqués de Cañete" (199, n. 2). 
posible a las escenas bélicas, a los combates de españoles y araucanos, según argumenta Germán Vega: "El número de dramatis personae no lo exige. Se trataría de engrosar los ejércitos castellano y araucano en aras de una mayor espectacularidad" (205). En la misma línea, Fausta Antonucci ha puesto de relieve que

nos encontramos con un texto que supone un espectáculo de cierto aparato: 18 actores en el reparto más comparsas y dos coros de música, desfiles de ejércitos, peñas que se abren y figuras que se hunden, sonidos de guerra y tempestades fingidas (32).

Por su parte, Miguel Zugasti ha comentado la abundancia de medios económicos con que se contó para la ocasión, lo que parece desprenderse no solo de la rumbosa representación sino además del hecho de que el texto se imprimiera exento, y con mucha calidad en comparación con lo que era habitual, ese mismo año de 1622:

Especial consideración merece el magno estreno que tuvo lugar en palacio en 1622 Algunas hazañas de las muchas de don Garcia Hurtado de Mendoza, marqués de Cañete, que corrió a cargo de dos compañías: la de Cristóbal de Avendaño y la de Pedro de Valdés [...] El texto se imprimió de forma independiente y en edición lujosa, lo que junto a la cantidad de colaboradores hace suponer que los Hurtado de Mendoza seguían perseverando en su tarea de autopromoción, ahora con el nuevo rey Felipe IV, recién llegado al trono (58).

En efecto, la publicación en Madrid, por Diego Flamenco, 1622, no se corresponde con la de una suelta al uso, sino de una edición mucho más cuidada en la que el texto de la comedia va antecedido por una portada que incluye el escudo nobiliario familiar y el pie de imprenta; se utiliza una buena tipografía y se añaden filetes y grabados de adorno, a lo que hay que sumar la inclusión de varias hojas preliminares con los "Personajes desta comedia"; una dedicatoria "Al marqués de Cañete" firmada por Belmonte (comienza: "Rasgos humildes y dibujos pequeños de las hazañas ilustres de don García Hurtado de Mendoza, marqués de Cañete, padre de Vuestra Señoría, están pidiendo con dichoso acuerdo un heroico mecenas que los ampare..."); y unas palabras dirigidas a los lectores, que van sin firma pero son también de Belmonte, donde los araucanos son presentados como "los indomables bárbaros de Chile" y se lee además lo siguiente: "El estado de Arauco, breve en el sitio, pues contiene solas diez y ocho leguas, está labrado con güesos 
de españoles, que con menos soldados de los que ha costado Chile se hizo Alejandro señor de todo Oriente"; y, en fin, la tabla de "Poetas que escribieron esta comedia", con una sumaria indicación de las partes redactadas por cada uno de ellos.

Son, por tanto, dos los indicios -el de la representación a cargo de dos compañías y el de la cuidada impresión exenta- los que parecen estar indicando que la familia apoyó con abundantes recursos económicos el proyecto de esta comedia. Y es que, como han destacado varios críticos (Ferrer, Vega, Dixon...), los Hurtado de Mendoza intentaron su autopromoción con Felipe IV, por medio de una campaña que se extendió por más de treinta años, para tratar de alcanzar -"al parecer sin el éxito esperado", matiza Ferrer (116)- las mercedes regias en reconocimiento a los muchos y buenos servicios prestados a la Corona por don García.

Otro detalle interesante que ha señalado la crítica, y que conviene hacer notar aquí, es que Algunas hazañas fue una pieza bastante popular que contó con numerosas representaciones en el Chile del siglo XVIII, según refiere el historiador Francisco Encina:

En la segunda mitad del siglo [se refiere al XVIII, y al territorio chileno] se generalizó la representación de verdaderas piezas teatrales, todas de autores españoles o peruanos. Parece que la más popular fue la intitulada Algunas hazañas de las muchas de Don García Hurtado de Mendoza, Marqués de Cañete, escrita en colaboración por siete [sic] ingenios (citado por Lerzundi, "Introducción”, 7).

\section{ALGUNAS HAZAÑNAS ANTE LA CRÍTICA}

La crítica se ha mostrado unánime al señalar la mala calidad de esta comedia, que se resiente precisamente, como ya he indicado, del propio carácter de obra en cuya composición intervinieron muchas plumas. En realidad, el principal defecto deriva de la circunstancia de la autoría múltiple, lo que hace que la acción no sea unitaria ni se desarrolle de forma coherente, sino que asistamos más bien a una sucesión de parlamentos excesivamente largos colocados unos detrás de otros. Mediocridad, falta de coherencia organizativa y de intensidad dramática, yuxtaposición de episodios y parlamentos (la palabra prevalece con mucho sobre la acción, grave defecto tratándose de una obra de teatro...), reiteraciones innecesarias, cabos sueltos e hilvanes a 
la vista en el "cosido" de las distintas piezas que forman la comedia, tales son los mayores defectos señalados por distintos estudiosos, algunas de cuyas opiniones acopiaré a continuación.

Muy negativa fue, por ejemplo, la de Marcelino Menéndez Pelayo, radical y tajante como otras muchas suyas: "En conjunto, la obra es monstruosa, como podía esperarse de un poema dramático repartido entre nueve personas que destrozan un texto histórico para hacer mangas y capirotes de él" (289). Bernard Moses se refería a ella como "mediocre work by a number of authors" (210). Para Rodolfo Usigli, se trata de un "vergonzoso engendro en general; se perciben todas las junturas, y caracteriza en su falta de unidad y en su desequilibrio los defectos capitales del teatro romántico español y ninguna de sus virtudes líricas" (citado por Lerzundi, 326-327). Lohman-Villena la presenta como "la desatinadísima comedia que compuso Belmonte con ocho ingenios más" (110); y opiniones similares de valoración negativa han sido vertidas por otros muchos críticos. Veamos por ejemplo este comentario de Mónica Lucía Lee:

En el análisis de Algunas hazañas... deben considerarse, pues, dos factores determinantes: el carácter apologético y la autoría múltiple. Ambos imponen restricciones que alteran el producto final; al primero se debe que la obra sea un compendio de escenas y desarrollo de temas destinados a ensalzar la figura de don García, en tanto que el segundo resulta en una obra estructurada como un "mosaico", cuyas piezas, si bien caben dentro de un patrón intencional y argumental común, difieren una de otras. Esta fragmentación resta coherencia al nivel de la fábula, resultando en una pieza pobremente estructurada (184).

También Vega ha insistido en la falta de coherencia organizativa, en el carácter deshilvanado de los distintos segmentos escénicos, así como en el desorden cronológico y la libertad en el uso de los datos por parte de los autores:

En relación con estos aspectos intertextuales, hay que subrayar la libertad en el manejo de los datos. La figura de Don García está ligada a una serie de episodios, gestos, palabras, que tienen un orden, más o menos respetado en las obras anteriores, aunque se pueden mencionar unos y callar otros. En nuestra comedia se selecciona y trastrueca la secuencia con total desparpajo. Cada autor parece gozar de más autonomía de la conveniente, para la coherencia del producto final, 
a la hora de escoger del plantel de episodios los que considera más oportunos $(207)^{12}$.

En fin, para Castillo, "la múltiple autoría fragmenta y deslavaza el hilo argumental y las conexiones internas de la acción para dar como resultado una comedia muy pobre" (116).

\section{EL RETRATO DE DON GARCÍA HURTADO DE MENDOZA EN ALGUNAS HAZAÑAS}

Pero me centraré ya en la imagen que de don García nos ofrece esta pieza dramática. Acierta Antonucci al señalar: "Evidentemente la comedia quiere construir en el personaje de don García un modelo de noble guerrero, y con este fin acentúa sus virtudes caballerescas" (33); y al añadir después:

El don García de los nueve dramaturgos no remite pues, a todas luces, al modelo lopesco del jefe-padre severo, sino a un modelo más moderado (aunque por lo visto también paternalista), el del jefe cortés, del jefe-amigo, que trata de entablar relaciones de paridad, más favorables al éxito de su programa de conquista (34).

Para Germán Vega:

El planteamiento de estos nueve plumíferos aduladores no ha sido el de erigir a D. García en protagonista de acciones virtuosas, como le correspondería al género dramático, sino, más bien, el de sacar a escena gente, de variada condición, que proclame una y otra vez que es virtuoso (207).

En fin, coincido plenamente con Castillo cuando afirma: "Se trata de una obra completamente encomiástica de la conquista y colonización de Chile sin la menor crítica a la actuación española en dicha empresa" (115).

$12 \quad Y$ añade: "Aunque la obra pretende conducirse intermitentemente por los cauces habituales del género de la comedia 'histórica', es decir, la guerra y el amor, son pocos los pasos que logran darse en la maraña de intervenciones desorganizadas. Más pendientes de hablar que de actuar, los guerreros andan huidizos y los enamorados se despistan. Toda la acción se resuelve en conatos de enfrentamiento, en idas y venidas de espías, traidores, desertores y amantes" (207). 
A continuación, iré comentando los hitos principales de la comedia, aquellos pasajes que me parecen más significativos en la construcción dramático-literaria del protagonista.

1) La primera mención de don García. Está puesta en boca de Galvarino, que se presenta con las manos cortadas en medio de la fiesta con que los araucanos están celebrando la victoria obtenida sobre Valdivia y Villagrán, bebiendo sangre en la calavera del primero, convertida en macabro vaso (ver para este motivo el trabajo de Donoso), y compitiendo entre ellos en pruebas de fuerza y habilidad. La alegría generalizada se ve interrumpida por la irrupción de Galvarino, quien avisa de la llegada de los españoles en seis navíos:

Galvarino Domar quieren a Arauco

sobre los reinos de Neptuno y Glauco,

y su gente gobierna

un joven de valor y fama eterna

que llaman don García

Hurtado de Mendoza, luz del día.

El marqués de Cañete

victorias desde Lima al rey promete;

la Fama al Virrey dijo

que Arauco está rebelde, y a su hijo,

mancebo bravo y fuerte,

envía con poderes de la muerte (vv. 230-241).

En este pasaje, correspondiente a la parte escrita por Mira de Amescua, me parece que no resulta gratuita la elección del verbo domar, en tanto en cuanto todos los espectadores sabrían que el resultado final de la acción del nuevo gobernador sería un Arauco domado (con un claro eco de los títulos de Oña y Lope).

2) La genealogía del marqués de Cañete. Cuando los araucanos, espoleados por la briosa arenga de Galvarino, van a lanzarse al combate, los detiene el anciano Colocolo, quien traza la genealogía del preclaro enemigo español:

Colocolo ¿Dónde vais a morir determinados cuando se os llega el postrimero día? ¿Habéis previsto el orden de los hados? ¿Sabéis quién es aqueste don García? Volved a detener los pies airados: 
no os admiréis de que la lengua mía os refiera de quién ha procedido, que en libros españoles lo he leído. Deste, pues, don García, cuya extraña majestad es de Júpiter desmayo, pues ya le tiembla la divina hazaña, de aquestas Indias generoso rayo, su primero ascendiente fue de España tan gran restaurador como Pelayo (vv. 260-273).

Ciertamente, en la realidad histórica era imposible, y así lo ha puesto de relieve la crítica $^{13}$, que Colocolo hubiese leído esa ascendencia de don García, y nada menos que "en libros españoles", pero la mención resulta especialmente significativa, precisamente porque el autor (se trata aquí de la contribución debida al conde del Basto) muestre al personaje araucano habiendo asimilado ya por completo el discurso del enemigo, de su futuro vencedor. Escribe Castillo a este respecto:

Algunas hazañas sigue en esto [en el resumen genealógico] los Hechos de Don García de Suárez de Figueroa; lo interesante es que aquí las gestas las narra un indio - mientras que en Ávila lo hace Don Luis y en Lope, Rebolledo- añadiendo así un grado más a la gloria que supone la empresa de los peninsulares (120).

Este pasaje estrictamente genealógico es bastante extenso (va desde el verso 274 hasta el 375) y se remonta desde los orígenes más remotos de la familia hasta el padre de don García. Concluye con una nueva alusión elogiosa, con la petición de Colocolo a los suyos para que no peleen contra quien es dominador de los elementos de la naturaleza (vv. 356-363).

3) La humildad de don García. En el siguiente bloque dramático, de Belmonte Bermúdez, el presunto coordinador de los nueve ingenios y autor él de un mayor número de versos, asistimos a la construcción de un fuerte. La escena sirve en esta ocasión para subrayar la humildad y el valor del capitán

13 Escribe Lee: "Las posibilidades de que Colo Colo supiera leer español y, más aún, de que tuviera acceso a textos sobre la genealogía del joven gobernador son más que escasas. Sin embargo, lo que interesa es cómo el autor da por sentado el proceso de asimilación del discurso español por el Nuevo Mundo" (189); y Vega García-Luengos: "nunca comprenderemos cómo se las ha arreglado para leer tantas crónicas españolas” (207). 
español, quien no duda en poner su esfuerzo y sus riquezas al servicio de la conquista. Reinoso pondera el ejemplo que da don García, quien ayuda a los soldados transportando él también espuertas de tierra con las que reforzar la fortificación, acción con la que dilata su fama "con prudencia y con valor" (v. 456). El ejemplo de un noble tan encumbrado que no le hace ascos al trabajo físico anima, claro está, a los soldados; pero no es solo eso, sino que don García ha mandado sacar las bandejas de plata de su ajuar para acarrear con ellas la tierra. Cuando don Felipe le indique que el valor se enoja de verlo en tan humilde acción (recordemos la idea extendida en aquella sociedad de que el trabajo manual era impropio de nobles, pues deshonraba), estas serán las palabras de respuesta de don García:

MARQuÉs Hoy haré mi nombre eterno

donde el vuestro el tiempo escriba,

porque en esta tierra estriba

el peso de mi gobierno.

Y así, dejando apariencias

de culpadas gravedades, siembro en la tierra humildades

para coger obediencias (vv. 500-507).

Así pues, este episodio cumple en la comedia de los nueve ingenios la función de poner de relieve la humildad de don García, pero no aparecerá aquí, en cambio, la escena del tenderse el gobernador al paso del Santísimo Sacramento (para que el sacerdote que lo porta pase por encima de él), de gran eficacia dramática, que está presente en el Arauco domado de Lope y en otras piezas.

4) La clemencia de don García. Toda la escena siguiente se refiere al episodio de Rebolledo (que tiene su precedente en la comedia lopesca), que ha quedado de posta en el lugar más peligroso, mirando a la campaña por donde se presume atacarán los araucanos. El soldado, solo, da muestras del miedo que le embarga y termina por quedarse dormido. Don García, general previsor que acude a supervisar personalmente las postas (porque "el descuido no dejó / honra ni lugar seguro", vv. 582-583), lo descubre pero lo perdona, pese a la gravedad de la falta, en atención al mucho trabajo y cansancio de la jornada. Don García se marcha y el soldado se vuelve a dormir. Reaparece el general, ahora muy enfadado y dando muestras de su rigor al mandar colgar de un roble al descuidado posta, porque la reiteración de una falta tan grave está poniendo en peligro la vida de todos, sin que le convenzan los ruegos de 
Reinoso ni de don Felipe: "Si este delito sufrimos, / no habrá en los demás cuidado" (vv. 674-675). Rebolledo pide al general que no lo mate, porque ya ha quedado muerto en la opinión (la pérdida del honor, según los códigos sociales del momento, era peor que la propia muerte física), pero afirma que renacerá como un hombre nuevo, "afrentado por dormir / y honrado por pelear" (vv. 706-707). Hecho este propósito de enmienda, don Felipe pide que le den una bandera a Rebolledo y, efectivamente, lo nombran inmediatamente alférez. La tensión dramática acumulada se diluye al rematarse la escena con un chiste del gracioso Chilindrón ${ }^{14}$, quien señala que, si se conceden banderas por dormir, él perfectamente podría ser maestre de campo ${ }^{15}$.

5) Su perspicacia para descubrir los engaños de los enemigos, que se evidencia en el episodio de la falsa embajada de Guacolda. Don García intuye que se trata de una falsa embajada de paz que tiene por objeto distraer a los españoles de las verdaderas intenciones de los araucanos, por lo que ordena dar tormento a Coquín, lo que suscita las quejas de la bella araucana: "No publica esa crueldad / tu fama" (vv. 772-773a). Pero aplicado efectivamente el tormento al indio, cuenta este que vienen contra ellos tres escuadrones de indígenas. Don Felipe comenta el malintencionado intento de entretenerlos por parte de la bárbara, pero el marqués, a fuer de español y caballero, perdona generosamente a Guacolda (vv. 826-836).

6) Las hazañas europeas de don García se recuperan en un diálogo entre Guacolda y Rebolledo, en el que además se acumulan varios calificativos como "hijo del Sol hermoso", "Gran discípulo de Marte"... (vv. 857-875). El soldado se refiere a su paso por Italia y Flandes, donde llevó a cabo numerosas hazañas:

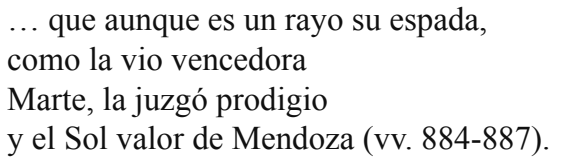

14 El contrapunto cómico de las acciones serias lo ponen los dos graciosos, el español Chilindrón y el araucano Coquín (ver Antonucci 35).

15 En Arauco domado se salva por el ingenio, al mencionar que Cristo perdonó a los discípulos que se quedaron dormidos en el Huerto de los Olivos mientras él oraba. 
Y se mencionan expresamente algunas de las batallas en las que participó antes de pasar al Perú (vv. 904-911), concluyendo de esta manera:

Rebolledo Este es el rayo de Arauco, que desde el cielo de Europa, Filipo, Júpiter nuevo, para abrasaros lo arroja (vv. 932-935).

7) Escasa presencia del elemento religioso, aspecto que en esta comedia no adquiere la importancia que sí tiene en otras piezas del corpus, en especial en El gobernador prudente ${ }^{16}$. Todo queda aquí en ligeros apuntes, como el contenido en este pasaje. Reinoso comenta que don García no quiere salir a la campaña hasta que pase el invierno. Los indios, argumenta un soldado, tal vez juzgarán esa decisión como señal de temor, pero Reinoso sentencia: "Verán su engaño las obras" (v. 971). Más adelante don García arengará a sus hombres para animarlos a pelear contra los araucanos, y es en las palabras de su hermano don Felipe donde apunta levemente el sentido providencialista de la conquista: "Si son de Dios las vitorias, / Él las dará a quien le sirve" (vv. 1039-1040).

8) El enfrentamiento personal con Caupolicán. Se da en algunos pasajes de la comedia la caracterización en paralelo de ambos caudillos, que no solo rivalizan en armas, sino también en cortesía ${ }^{17}$. En efecto, en el momento del ataque de los indios al fuerte español, don García se enfrentará cuerpo a cuerpo al toqui araucano (vv. 1041-1049). En medio del combate, Orompello logra entrar en el fuerte, mientras que el reformado Rebolledo, que ha perdido su arma, se echa fuera de la empalizada para pelear contra los indios. Caupolicán, que ve el valor con que se defiende, ordena que no lo ataquen varios, sino solamente Orompello. A su vez, cuando los españoles vayan a disparar sus

16 Es aspecto ya señalado por Antonucci: "El protagonista aquí también es don García, cuyo personaje encarna sin embargo un modelo muy distinto del modelo lopesco. Es, en primer lugar, un modelo más laico, en el que faltan todos los episodios de devoción religiosa representados en Arauco domado. La humildad de don García se nos presenta ahora como la virtud del jefe que no rehúsa compartir el trabajo y las dificultades de sus inferiores" (32-33).

17 Es algo muy similar a lo que sucedía en los romances fronterizos, o en la deliciosa novela morisca Historia del Abencerraje y de la hermosa Jarifa, entre personajes moros y cristianos que entablaban una lucha caballeresca de valor, honor y galanía. Ver Antonucci 33-34. 
arcabuces, don García lo impedirá por ser "acción vergonzosa”: “¿Pues no fuera afrenta / que estos bárbaros conozcan / la ley de la cortesía, / pues la publican con obras, / y que me faltase a mí?” (vv. 1092-1096). Y luego Caupolicán y don García pelearán cuerpo a cuerpo (ver vv. 1179-1217 acot.). Luego, al comienzo de la segunda jornada, en el tramo dramático de Ruiz de Alarcón, don García en diálogo con Chilindrón pondera que su actuación se mueve por el deseo de aumentar la fama y el honor de sus antepasados (vv. 1258b-1275).

9) Su cortesía con el enemigo, incluso cuando este intenta atentar contra su vida. La excusa es una nueva embajada de paz cuyas condiciones (que incluyen la retirada de los españoles) él no puede aceptar. Rechaza igualmente una corona de flores que se le ofrece, pues la acción de ser coronado -explicacorresponde únicamente a su soberano. En realidad, la embajada de paz ocultaba un plan de atentado contra don García, que falla porque a Nacol se le cae la daga que lleva escondida entre las flores. Una vez más, don García da muestras de su nobleza al perdonar a sus agresores (ver vv. 1516-1525 y 1532-1543), y ambos, Tucapel y Nacol, no pueden menos que reconocer su valor (vv. 1568-1571) y dedicarle nuevos elogios.

10) La resolución militar de don García. En el pasaje siguiente, correspondiente a Vélez de Guevara, don García dialoga con su hermano. Comentan que los indios les temen ya, pues tratan de paces. Un indio mensajero del Cagueyano, cacique amigo, advierte al "general noble y valiente" (v. 1591) para que salve su vida, pues se lanzan contra él copiosos escuadrones que suman más de 40.000 indios, y enumera a sus principales caudillos. Don García decide ir a esperarlos cruzando al otro lado del río, "y así será el despreciarlos / comenzarlos a vencer" (vv. 1614-1615). Esa arriesgada decisión de cruzar el caudaloso Nibequetén se equipara a la de César de pasar el Rubicón (vv. 1636-1649; se trata de un elemento de la Antigüedad romana puesto al servicio del panegírico).

11) Su carácter galante o, por mejor decir, su caballerosidad con las damas. En esta comedia no vemos a don García implicado en una trama amorosa con una india (ver Mata Induráin, "Cautivo quedo en tus ojos"), pero sí apunta algún detalle de su caballerosidad en la escena en que describe cómo cruza el río Gualeva. Don García usa un lenguaje galante, con imágenes y metáforas cultistas, al describir la acción de la india y su belleza (vv. 1678b-1695). A su vez, las palabras de la india acumularán nuevos elogios dedicados al 
gobernador: "español Atlante" (v. 1710), "Hijo del sol, dios del mar, / Apó de la Europa" (vv. 1816-1817), etc.

13) Su valentía en el combate, peleando al frente de los suyos para contagiarles su valor. El acto tercero comienza con el pasaje de don Jacinto de Herrera en el que don García arenga a los españoles para que ganen una montaña a los araucanos, de la misma forma que Caupolicán lo hace con los suyos; pero él da ejemplo a todos corriendo el primero al asalto (vv. 21312134). Después, el mágico Leocotán vaticina la derrota de los araucanos y el creciente poder de don García, quien (se trata de un motivo muy reiterado) vencerá nueve batallas y fundará nueve ciudades (vv. 2261-2300), añade todavía un largo elogio (vv. 2303-2330) con una clara función de prolepsis: de la misma forma que don García ha heredado el valor de su padre, el hijo que en España le cría su mujer heredará sus virtudes: don Juan Andrés, impulsor por estos años de la campaña de propaganda familiar y mecenas, por tanto, de esta comedia donde se le elogia en vaticinio por boca del mágico araucano. En fin, concluye Leocotán que para los suyos lo mejor es rendirse, pues todo está a favor de los españoles (vv. 2361-2380).

14) Nuevos elogios de don García como soldado valeroso y general prudente. Cuando Reinoso prende a Caupolicán no está presente don García, pero el capitán español reconoce que todo lo pueden los que pelean con su general: "Tu osadía / no en mí solo el triunfo emplea, / que esto puede quien pelea / en nombre de don García" (vv. 2467b-2470). Más adelante, en la contribución de Guillén de Castro, don García se asombra de ver tan bien labrado un fuerte que han preparado sus hombres, y su hermano don Felipe le ofrece esta explicación: "tú los enseñaste / a ser soldados, señor" (vv. 2807-2808). Se preparan para el ataque 14.000 araucanos, y los españoles solo son 200, pero no hay nada que temer porque don García pelea al frente de los suyos (vv. 2827-2832). Ya señalaba antes que el elemento religioso se hace poco presente en esta obra, pero apunta de nuevo brevemente en estas palabras de don García:

MARQuÉs Siendo Dios de nuestra parte,

la ventaja es nuestra: vea,

pues por nosotros pelea

nuestro Dios, que es nuestro Marte.

¡Ea, ea, al arma toca!

¡Santiago, Santiago! (vv. 2833-2838). 
Don García alienta a los soldados españoles cuando se retiran (vv. 28452852 y 2855-2856) y su valor es ponderado por Chilindrón, en una escena ticoscópica (vv. 2857-2872). Se ensalza, pues, su esfuerzo personal en el combate, al pelear al frente de los suyos, arriesgando su vida. Don Felipe, su hermano, le dice que es locura que se exponga en la batalla el general en jefe de las tropas, pero él responde que "Alejandro peleó / y Julio César también" (vv. 2879-2880).

15) Su actuación, en la parte final, con relación al bautismo y muerte de Caupolicán (los acontecimientos finales, igual que sucede en El gobernador prudente de Ávila, se presentan aquí de forma distinta al desenlace del Arauco domado de Lope, diluyendo la responsabilidad de don García en la muerte del toqui araucano). El soldado que llega a anunciarle que Reinoso ha prendido a Caupolicán lo saluda de esta manera:

SOLDADO Ilustre blasón de España, Mendoza al fin, que has traído yugo a Arauco no vencido, terror ya de su campaña, el cielo tu esfuerzo ayuda (vv. 2901-2905).

Le cuenta que aquel ha sentenciado a muerte al indio: Reinoso es sobrino de Valdivia, y quiere vengar ahora el escarnio de la calavera convertida en copa para las libaciones. Don García señala que tal acción ha sido excesivamente rigurosa; don Felipe y Rebolledo interceden por Caupolicán y don García indica: "Hoy pienso, por socorrelle, / pasar sin pisar el valle" (vv. 2935-2936). Vemos luego que Caupolicán, bautizado como Pedro ${ }^{18}$, se muestra feliz: "muriendo estoy por morir" (v. 2968). Gualeva le reprocha su rendición, pues se ha humillado y los ha humillado a todos, y se ofrece para ser su verdugo. Caupolicán le responde: "dichosamente tengo / honor nuevo y alma nueva" (vv. 2999-3000). Y estando ya empalado reconoce que "El gran Dios de los cristianos / es solo Dios verdadero" (vv. 3005-3006), en un pasaje en el

18 Un nuevo Pedro/piedra sobre la que asentar la Iglesia de Cristo en Arauco; escribe Castillo: "Es este 'Pedro', a imagen y semejanza de la figura bíblica, el personaje sobre el que Don García edificará la evangelización de todo el territorio" (123). 
que, tanto en las palabras como en las acciones, podemos apreciar ciertas reminiscencias cristológicas ${ }^{19}$.

En fin, al propio Luis de Belmonte le correspondió, o él mismo se reservó para sí, la redacción del tramo final de la obra, siendo así el único dramaturgo que aporta dos pasajes al conjunto. Al llegar don García, reprocha duramente a Reinoso por haber matado a un enemigo que tenía rendido como prisionero indefenso, y no frente a frente en el campo de batalla (vv. 3051-3060). Emplea un tono muy duro, y apela incluso a razones de Estado al decir que habría sido mucho más útil conservar la vida de un preso tan valioso (vv. 3061-3086). Don Felipe intercede por Reinoso, pero don García está resuelto a castigarlo: "Sepa el rey que a un hecho injusto / castigo justo le doy" (vv. 3099-3100). El hermano del gobernador alega en defensa del capitán el argumento, ya antes mencionado, de que el caudillo araucano había matado a su tío Valdivia, pero este razonamiento no le sirve a don García. La cita que sigue es importante:

MARQUÉS No, hermano: jamás alcanza

la vitoria la venganza.

Este es el oficio mío:

pues premio, he de castigar (vv. 3114-3117).

Por su parte, Caupolicán, en medio de su tormento -sigue empalado en escena-, se muestra agradecido a su enemigo:

CAupolicán Don Felipe, mucho debo al gran Marqués, pues que miro que voy por su causa al cielo por tan seguro camino (vv. 3129-3132).

Tras la cristiana muerte del toqui, los indios de la belicosa Arauco quedan por fin sojuzgados al poder, no de don García sino del rey de España, en cuyo nombre sabrá ser clemente y gobernar con justicia (tal como refleja el diálogo de los vv. 3148-3174). Finalmente, se procede al reparto de premios y mercedes. Don García se ofrece para ser el padrino en la boda de Rengo y Guacolda, que se convierten al cristianismo y se van a bautizar. Afirma que el rey premiará a Rebolledo; y ninguno de sus soldados quedará "sin el

19 Detalle interesante para relacionarlo con el auto sacramental de La Araucana, donde Caupolicán con el tronco a hombros es trasunto de Cristo con el madero de la cruz. Ver Mata Induráin, "La Guerra de Arauco en clave alegórica". 
premio merecido, / aunque de mi hacienda sea" (vv. 3190-3191). El ultílogo le corresponde al propio Rebolledo:

Rebolledo Y aquí Arauco, aquí su invicto conquistador tenga fin, aunque en la fama infinito (vv. 3192-3194).

Un detalle importante, para finalizar. El interlocutor último (o el primero, según se mire...) de este mensaje relativo a premios y mercedes no podía ser otro, dada la intencionalidad de la obra, que el propio rey de España, el cual habría asistido a la representación de la comedia en Palacio. La lección estaba clara y, además, a buen entendedor pocas palabras bastan: si don García había sabido ser generoso con los suyos, con todos los que le habían servido bien, igualmente debería serlo el monarca premiando espléndidamente a la familia de los Hurtado de Mendoza, en justa recompensa de los magníficos esfuerzos y servicios prestados a la Corona por uno de sus mejores servidores en Europa y América: don García Hurtado de Mendoza.

\section{A MODO DE CONCLUSIÓN}

Cabe destacar que en esta comedia de nueve ingenios, la cual forma parte de la campaña de propaganda que la familia Hurtado de Mendoza desarrolló durante tres décadas largas, se pone más de relieve la actuación militar de don García, como sucede también en el Arauco domado de Lope, y no se atiende tanto a su faceta de gobernador prudente, nuclear en la obra de Ávila ya desde su propio título, ni se incide tampoco en los elementos religiosos. Desde el punto de vista literario, Algunas hazañas se nos presenta como una obra de desigual calidad y de poca enjundia dramática. Con escasa acción sobre las tablas, pese a las idas y venidas de tantos personajes, se deja todo a la fuerza de la palabra y prevalece la yuxtaposición de largos parlamentos por sobre la acción, que no queda dramáticamente bien imbricada ${ }^{20}$. Es posible que cabo son las palabras, las muchas palabras enhebradas en interminables parlamentos. Hay una confianza sin límites en la fuerza de las palabras, tanto en las dichas como en las escritas. [...] Por el contrario, la acción, sustancia específica de lo dramático, no va a ningún lado" (207). 
la colaboración de los nueve ingenios pretendiera emular, como sugirieron algunos estudiosos, a las nueve musas; pero ya se ve que estas debían de andar distraídas en aquella ocasión, u ocupadas tal vez en otros asuntos más importantes, pues resulta patente que no les brindaron toda su inspiración y que, en justa consecuencia, los resultados dramático-literarios logrados por los nueve dramaturgos dejan mucho que desear.

\section{BIBLIOGRAFIA}

Algunas hazañas de las muchas de don García Hurtado de Mendoza, marqués de Cañete. En Madrid: por Diego Flamenco, año 1622. Ejemplares en la Biblioteca Nacional de España (BNE), signs. R/10.352, R/30.787 y R/36.664, y en la Real Academia Española, sign. 41-II-38.

Edited and annotated, with an Introduction, by Patricio C. Lerzundi, with a Preface by Marlene Gottlieb. Lewiston / Queenston / Lampeter: The Edwin Mellen Press, 2008.

En Comedias de don Juan Ruiz de Alarcón y Mendoza, colección hecha e ilustrada por don Juan Eugenio Hartzenbusch. Madrid: M. Rivadeneyra, 1852 [nuevas ediciones en 1857 y 1946] (BAE, tomo XX). 487-508.

Ed. de Eduardo Juliá Martínez. En Obras de don Guillén de Castro y Bellvis. Vol. III. Madrid: Tipografía de la Revista de Archivos, 1927. 593-639.

Ed. de Agustín Millares Carlo. En Juan Ruiz de Alarcón. Obras completas. Vol. III. México: Fondo de Cultura Económica, 1968. 535-628.

Antonucci, Fausta. "El indio americano y la conquista de América en las comedias impresas de tema araucano (1616-1665)". Relaciones literarias entre España y América en los siglos XVI y XVII. Coord. Ysla Campbell. Ciudad Juárez: Universidad Autónoma de Ciudad Juárez, 1992. 21-46.

Baraibar, Álvaro. "Chile como un "Flandes indiano" en las crónicas de los siglos XVI y XVII". Revista Chilena de Literatura (2013), en este mismo número.

Campos Harriet, Fernando. Don García Hurtado de Mendoza en la Historia Americana, Santiago: Editorial Andrés Bello, 1969.

Carrasco Urgoiti, María Soledad. "En torno a La luna africana, comedia de nueve ingenios". Papeles de Son Armadans año IX, tomo XXXII, 96 (1964): 255-298.

Cassol, Alessandro, y Juan Matas Caballero, eds. La escritura en colaboración en el teatro áureo. Valladolid: Universidad de Valladolid-Secretariado de Publicaciones e Intercambio Editorial, en prensa.

Castillo, Moisés R. Indios en escena: la representación del amerindio en el teatro del Siglo de Oro. West Lafayette (Indiana): Purdue University Press, 2009.

Dixon, Victor. "Lope de Vega, Chile and a Propaganda Campaign". Bulletin of Hispanic Studies LXX (1993): 79-95. 
Donoso, Miguel. "Pedro de Valdivia tres veces muerto". Anales de Literatura Chilena 7 (2006): 17-31.

Ercilla, Alonso de. La Araucana. Ed. de Isaías Lerner. Madrid: Cátedra, 1993.

Fernández-Guerra y Orbe, Luis de. Don Juan Ruiz de Alarcón y Mendoza. Madrid: Imprenta y Estereotipia de Rivadeneyra, 1871.

Ferrer Valls, Teresa. Nobleza y espectáculo teatral (1535-1622). Estudio y documentos. Sevilla / Valencia: UNED / Universidad de Sevilla / Universitat de València. 1993.

Lee, Mónica Lucía. De la crónica a la escena: Arauco en el teatro del Siglo de Oro. Columbia: University of British Columbia, 1993.

Lerzundi, Patricio C. Arauco en el teatro del Siglo de Oro. Valencia: Albatros Hispanófila Ediciones, 1996.

"Introducción". Algunas hazañas de las muchas de don García Hurtado de Mendoza, Marqués de Cañete. Lewiston / Queenston / Lampeter: The Edwin Mellen Press, 2008. 1-13.

Lohman-Villena, Guillermo. Arte dramático en Lima durante el Virreinato. Madrid: Escuela de Estudios Hispano-Americanos, 1945.

Mata Induráin, Carlos. "Cautivo quedo en tus ojos: el cautiverio de amor en el teatro del Siglo de Oro sobre la conquista de Arauco". El cautiverio en la literatura del Nuevo Mundo. Eds. Miguel Donoso, Mariela Insúa y Carlos Mata. Madrid / Frankfurt: Iberoamericana / Vervuert, 2011. 169-193.

"La Guerra de Arauco en clave alegórica: el auto sacramental de La Araucana". Alpha 33 (2011): 171-186.

"El imaginario indígena en el Arauco domado de Lope de Vega". Taller de Letras número especial 1 (2012). 229-252.

"El imaginario indígena y la justificación de la conquista de América en El gobernador prudente de Gaspar de Ávila”. En prensa.

Matas Caballero, Juan. "El Arte nuevo de hacer comedias y la comedia en colaboración". En Cuatrocientos años del "Arte nuevo de hacer comedias" de Lope de Vega. Coords. Germán Vega García-Luengos y Héctor Urzáiz Tortajada. Valladolid: Universidad de Valladolid-Secretariado de Publicaciones e Intercambio Editorial, 2010. Vol. 2. 715-728.

"La officina poetica de una comedia colaborada: La mejor luna africana". En La escritura en colaboración en el teatro áureo. Eds. Alessandro Cassol y Juan Matas Caballero. Valladolid: Universidad de Valladolid-Secretariado de Publicaciones e Intercambio Editorial, en prensa.

Menéndez Pelayo, Marcelino. Estudio preliminar. Obras de Lope de Vega. Madrid: Sucesores de Rivadeneyra, 1890. Vol. XII.

Morán Martín, Remedios. "García Hurtado de Mendoza ¿gobernador o héroe”. Espacio, Tiempo y Forma. Serie IV, Historia Moderna 7 (1994): 69-86.

Moses, Bernard. Spanish Colonial Literature in South America. New York: HSA, 1922.

Romanos, Melchora. "La construcción del personaje de Caupolicán en el teatro del Siglo de Oro”. Filología XXVI, 1-2 (1993): 183-204.

Sommer-Mathis, Andrea, et al. El teatro descubre América. Fiestas y teatro en la Casa de Austria (1492-1700). Versión española de Társila Reyes Sicilia. Madrid: Editorial MAPFRE, 1992. 
Suárez de Figueroa, Cristóbal. Hechos de don García Hurtado de Mendoza, cuarto marqués de Cañete... En Madrid: en la Imprenta Real, 1613.

Varey, John E. y Norman D. Shergold. "Some Palace Performances of Seventeenth Century Plays”. Bulletin of Spanish Studies XL (1963): 212-244.

Comedias en Madrid: 1603-1709. Repertorio y estudio bibliográfico. London: Tamesis Books, 1989.

Vega García-Luengos, Germán. "Las hazañas araucanas de García Hurtado de Mendoza en una comedia de nueve ingenios. El molde dramático de un memorial". Edad de Oro X (1991): 199-210.

Zugasti, Miguel. "El encargo literario". Las palabras a los reyes y gloria de los Pizarros by Luis Vélez de Guevara. Eds. William R. Manson y George Peale. Newark (Delaware): Juan de la Cuesta, 1996. 49-86. 